\title{
Biodegradable magnesium nanoparticle-enhanced laser hyperthermia therapy
}

This article was published in the following Dove Press journal:

International Journal of Nanomedicine

27 August 2012

Number of times this article has been viewed

\section{Qian Wang' \\ Liping Xie' \\ Zhizhu $\mathrm{He}^{2}$ \\ Derui $\mathrm{Di}^{2}$ \\ Jing Liu ${ }^{1,2}$}

'Department of Biomedical

Engineering, School of Medicine, Tsinghua University, ${ }^{2}$ Key Laboratory of Cryogenics, Technical Institute of Physics and Chemistry, Chinese Academy of Sciences, Beijing,

People's Republic of China
Correspondence: Jing Liu Department of Biomedical Engineering, School of Medicine, Tsinghua University, Beijing 100084, People's Republic of China Tel +861062794896

Fax +8610 82543767

Email jliubme@tsinghua.edu.cn
Background: Recently, nanoparticles have been demonstrated to have tremendous merit in terms of improving the treatment specificity and thermal ablation effect on tumors. However, the potential toxicity and long-term side effects caused by the introduced nanoparticles and by expelling them out of the body following surgery remain a significant challenge. Here, we propose for the first time to directly adopt magnesium nanoparticles as the heating enhancer in laser thermal ablation to avoid these problems by making full use of the perfect biodegradable properties of this specific material.

Methods: To better understand the new nano "green" hyperthermia modality, we evaluated the effects of magnesium nanoparticles on the temperature transients inside the human body subject to laser interstitial heating. Further, we experimentally investigated the heating enhancement effects of magnesium nanoparticles on a group of biological samples: oil, egg white, egg yolk, in vitro pig tissues, and the in vivo hind leg of rabbit when subjected to laser irradiation.

Results: Both the theoretical simulations and experimental measurements demonstrated that the target tissues injected with magnesium nanoparticles reached much higher temperatures than tissues without magnesium nanoparticles. This revealed the enhancing behavior of the new nanohyperthermia method.

Conclusion: Given the unique features of magnesium nanoparticles - their complete biological safety and ability to enhance heating - which most other advanced metal nanoparticles do not possess, the use of magnesium nanoparticles in hyperthermia therapy offers an important "green" nanomedicine modality for treating tumors. This method has the potential to be used in clinics in the near future.

Keywords: laser thermal therapy, heating enhancer, biodegradability, nanohyperthermia, bioheat transfer

\section{Introduction}

Cancer is a major public health problem all over the world. Currently, one in four deaths in the USA are caused by cancer, and the incidence of cancer continues to increase. ${ }^{1}$ Among the many endeavors developed to combat cancer, nanotechnology offers new hope to fight cancer. ${ }^{2,3}$ In 2003, Hirsch et al applied gold nanoshells, which comprise a gold layer over a silica core, to treat human breast carcinoma cells in vitro. ${ }^{4}$ The carcinoma cells were found to have undergone photothermally induced morbidity on exposure to near infrared (NIR) light. They also used human epidermal growth factor receptor-2 (HER2)-targeted gold nanoshells to treat the breast cancer cell line overexpressing HER2. ${ }^{5}$ Following exposure to NIR laser light, the dual imaging/therapy immuno-targeted nanoshells can selectively induce cells that overexpress HER2 to die. 
Huang and colleagues have demonstrated that gold nanorods have a longitudinal absorption band in NIR light on account of their surface plasmon resonance oscillations and are effective as photothermal agents. ${ }^{6}$ Further, Huang et al have demonstrated that gold nanorods conjugated to antiepidermal growth factor receptor (anti-EGFR) antibodies could selectively target cell lines that overexpress EGFR. Subsequent continuous laser exposure of nanoparticle-treated cells resulted in photothermal destruction of the EGFR positive cells at half the energy required to kill EGFR negative cells. ${ }^{7}$ Chen et al have investigated the photothermal destruction of cancer using gold nanocages in vitro and in vivo. ${ }^{8}$ The results revealed that the strong absorption of light by gold nanocages could generate enough heat to kill cancer cells. Carbon nanotubes have also been considered for applications in various biological systems. ${ }^{9}$ The combination of nanotechnology with medicine has thus yielded important advances in the fight against cancer. Overall, nanoparticles have shown high promise for application in hyperthermic cancer therapy. However, most of these nanoparticles are not degradable in the human body and thus are still required to be less cytotoxic to the surrounding normal cells. In fact, important evidence has shown that many of the tested nanoparticles, including the well-known gold nanoparticles, unfortunately have varying degrees of toxicity. ${ }^{10}$

As is well-known, $\mathrm{Mg}^{2+}$ is one of the most abundant divalent cations in living cells and it plays a vital role in many cellular processes. The recommended dietary allowance of magnesium is $300 \mathrm{mg}$ /day for a nonpregnant adult woman and $350 \mathrm{mg}$ /day for an adult man. An adult human body contains about $25 \mathrm{~g}$ of magnesium and it is the second most abundant intracellular element in the body. About $1 \%$ of the total body magnesium is found in blood plasma, about a third of which is bound to proteins. ${ }^{11,12}$ In fact, magnesium has recently become a promising material of tremendous interest as a biocompatible and biodegradable implant metal, with its alloys continuing to be proven excellent candidate materials for biodegradable orthopedic implants ${ }^{13}$ and vascular stents. ${ }^{14}$ Overall, the safety of the magnesium nanoparticle lies in its degradation into magnesium ions, which are completely absorbable by the human body. Magnesium nanocomposites have also been used for hydrogen storage.$^{15}$ However, as far as the authors are aware, until now, no research has been undertaken on introducing such an interesting material in nanoscale into tumor therapy, especially into the area of laser nanohyperthermia. In this study, due to its high heat conductivity and uniquely perfect biodegradability, ${ }^{16}$ we proposed for the first time to adopt magnesium nanoparticles for enhancing cancer hyperthermia therapy with the assistance of an NIR laser. To investigate the basic features of this new nanohyperthermia modality, theoretical and experimental evaluations were carried out. The same strategy can probably be extended to other areas in nanomedicine.

\section{Principles, materials, and methods Theoretical model and calculation method}

To understand the basic behavior of magnesium nanoparticleenhanced laser heating, a computational model was set up, as shown in Figure 1. Briefly, we considered that the nanoparticles were distributed uniformly. The laser needle was inserted into the center of the simulated model to emit energy. Theoretically, the transmission of photons from the laser beam to the surrounding tissues can be expressed as follows:

$$
s \cdot \nabla I(r, \hat{s})+\mu_{t} I(r, \hat{s})=\frac{\mu_{t}}{4 \pi} \int_{4 \pi} p\left(\hat{s}, \hat{s}^{\prime}\right) I\left(r, \hat{s}^{\prime}\right) d w^{\prime}
$$

where $r$ is the position vector; $\hat{s}, \hat{s}^{\prime}$ are direction vectors; $I(r, \hat{s})$ is the intensity of laser light at position $r$ in $\hat{s}$ direction; $w^{\prime}$ is the solid angle; $\mu_{t}$ is the total attenuation coefficient defined as the sum of the absorption coefficient, $\mu_{a}$, and the scattering coefficient, $\mu, p\left(\hat{s}, \hat{s}^{\prime}\right)$, is the phase function. This equation as well as its initial and boundary conditions was simulated by the Monte-Carlo method to obtain the optical energy distribution in the model.

To predict the effects of the magnesium nanoparticleenhanced laser heating on the target tissues, bioheat transfer equations were used to characterize the temperature field. For tissue area, the classic Pennes equation was adopted, which generally reads as:

$$
\rho_{t} c_{t} \frac{\partial T_{t}}{\partial t}=\nabla\left[\lambda_{t} \nabla T_{t}\right]-W_{b} c_{b}\left(T_{t}-T_{b}\right)+Q_{t m}+Q_{t r}
$$

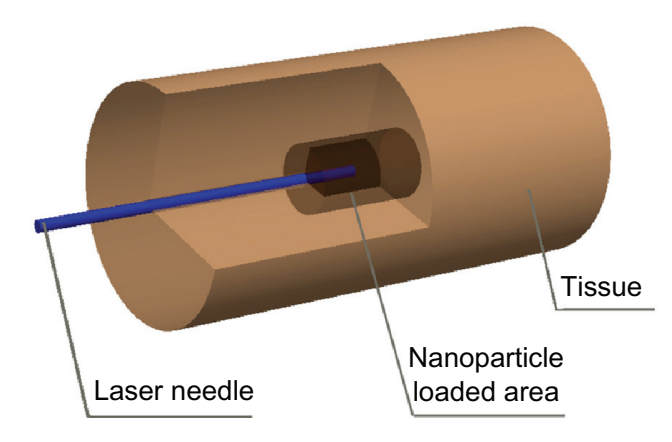

Figure I Sketch of the computational two-layer model. 
where $\rho$ is the density, $c$ is the heat capacity, $\lambda$ is the thermal conductivity, $W_{b}$ is the blood perfusion rate, $Q_{m}$ is metabolic heat generation, $Q_{r}$ is the volumetric heat source due to spatial heat generation, and $t$ and $b$ denote tissue and blood, respectively.

To safely irradiate using a laser, the surface of the laser beam must be cooled. In this study, water was often adopted as the cooling medium. Therefore, the heat transfer equation to characterize the cooling water domain can be expressed as:

$$
\rho_{\mathrm{w}} c_{\mathrm{w}}\left(\frac{\partial T_{\mathrm{w}}}{\partial t}+\mathrm{V} \nabla T_{\mathrm{w}}\right)=\nabla\left[\lambda_{\mathrm{w}} \nabla T_{\mathrm{w}}\right]+Q_{r}
$$

where $\mathrm{V}$ is the velocity for the cooling water and $\mathrm{w}$ denotes water.

Clearly, the addition of nanoparticles would change the optical properties of the tissues. The absorption and scattering coefficient of tissue equations following nanoparticle loading are therefore prescribed as:

$$
\mathrm{Coe}_{\text {mix }}=\eta \mathrm{Coe}_{n p}+(1-\eta) \text { Coe }_{\text {tissue }}
$$

where $\eta$ is the volumetric concentration of the nanoparticles, which depends on the number of particles per unit volume $n$ and particle radius $R_{n p}$; that is:

$$
\eta=n\left(4 \pi R_{n p}^{3 / 3)}\right.
$$

Similarly, other tissue properties would also change, such as the values of density, specific heat, and thermal conductivity for the tissues loaded with nanoparticles. These can be modified thus:

$$
\begin{gathered}
\rho_{\text {mix }}=\eta \rho_{n p}+(1-\eta) \rho_{\text {tumor }} \\
c_{\text {mix }}=\eta c_{n p}+(1-\eta) c_{\text {tumor }} \\
\frac{1}{\lambda_{\text {mix }}}=\frac{\eta}{\lambda_{n p}}+\frac{(1-\eta)}{\lambda_{\text {tumor }}}
\end{gathered}
$$

A similar calculation method has been previously demonstrated in Wang et al's work, in which gold nanoshells were used to enhance laser heating; readers are referred to their study for more details. ${ }^{17}$

\section{Experimental set up}

The magnesium nanoparticles used for the nano laser heating experiments in this study are commercially available and were directly purchased from Beijing Nachen S\&T Ltd (Beijing, China). ${ }^{18}$ For conceptual experiments, only the commercially available magnesium nanoparticles with a specified average diameter of $80 \mathrm{~nm}$ were tested in this study. A detailed comparison of the heating enhancement effects resulting from variable sizes and structures of these particles therefore needs to be researched in the future. It is worth noting that in this study only pure magnesium was used, which is often black in color. Such pure (99.9\%) metal particle material is stored in vacuum packaging to avoid oxidation. Because the properties of magnesium nanoparticles, such as high heat conductivity and uniquely perfect biodegradability ${ }^{16}$ have been well addressed previously, in this study we focused on evaluating their heating enhancement effects. In contrast to pure magnesium, the oxidized magnesium nanoparticle - that is, the $\mathrm{MgO}$ nanoparticle - is generally white in color, thus almost does not absorb laser light. It is therefore of limited use for heating enhancement and was not our current concern. Magnesium nanoparticles are not very reactive with water below a certain temperature, such as the body core temperature of $37^{\circ} \mathrm{C}$. Therefore, a suspension fluid containing the nanoparticles with an initial temperature around room temperature, $25^{\circ} \mathrm{C}$, can easily be injected into the target sample or tissues.

A diode laser system (KS3-11311-106; BWT Beijing Ltd, Beijing, China) was used to administer laser radiation as the heating source. An infrared camera (ThermoVision ${ }^{\circledR}$ A40; FLIR Systems, Wilsonville, OR) was used to record the dynamic thermal images of the heated materials. The internal temperature of the tested objects was monitored by a thermocouple and data acquisition system (Agilent 34970; Agilent Technologies, Santa Clara, CA).

In this study, we designed four cases to measure the temperature changes of the materials administered magnesium nanoparticles then subjected to laser heating. Each case comprised several experimental samples (Table 1). In addition, each experiment was performed twice and the result was the average value from these two tests.

Figure 2 illustrates the experimental setup of Cases A and $\mathrm{B}$. The temperature of $10 \mathrm{~mL}$ of liquid in a beaker was measured with thermocouples. For Case A, three thermocouples were used, one each to measure the room temperature and the temperatures at the bottom and the middle of the liquid. As water may react to magnesium nanoparticles under high temperature, oil was used here to reveal the basic features of the new nanohyperthermia modality, in which the heating effect was caused mainly by the laser absorbance of the magnesium nanoparticles; in the future, for the practical injection of magnesium nanoparticles into biological tissues containing water, a nanosuspension with 
Table I Experimental groups

\begin{tabular}{lll}
\hline Group & No & Sample \\
\hline Case A & I & Oil \\
& 2 & Oil $+0.02 \mathrm{~g} / \mathrm{mL}$ NPs \\
& 3 & Oil $+0.05 \mathrm{~g} / \mathrm{mL}$ NPs \\
& 4 & Oil $+0.2 \mathrm{~g} / \mathrm{mL} \mathrm{NPs}$ \\
Case B & 5 & Egg white \\
& 6 & Egg white $+0.02 \mathrm{~g} / \mathrm{mL}$ NP aqueous solution \\
& 7 & Egg yolk \\
& 8 & Egg yolk $+0.02 \mathrm{~g} / \mathrm{mL}$ NP aqueous solution \\
Case C & 9 & Pig tissue $+0.1 \mathrm{~mL}$ water \\
& I0 & Pig tissue $+0.1 \mathrm{~mL}$ of $0.01 \mathrm{~g} / \mathrm{mL} \mathrm{NP}$ aqueous solution \\
& II & Pig tissue $+0.1 \mathrm{~mL}$ of $0.02 \mathrm{~g} / \mathrm{mL} \mathrm{NP}$ aqueous solution \\
Case D & I2 & Hind leg of rabbit + I $\mathrm{mL}$ water \\
& I3 & Hind leg of rabbit + I $\mathrm{mL}$ of $0.02 \mathrm{~g} / \mathrm{mL}$ NP aqueous \\
& & solution
\end{tabular}

Abbreviation: NP, nanoparticle.

a temperature below that of the body core will fulfill this requirement.

For Case B, using egg white and egg yolk, two thermocouples were used to measure temperature, one for the room temperature and the second for the temperature at the middle of the liquid. Egg was used because egg white and egg yolk are simple biological tissues that were suitable for testing the new nanohyperthermia modality. In particular, the heating phenomenon is easy to observe in these two materials. Egg white is mostly composed of protein, while egg yolk consists of protein, fat, and water.

Case $\mathrm{C}$ used the muscle tissue of pig as a test model. The size of the muscle tissue was $3 \mathrm{~cm}^{3}$ and the injection depths for samples $9,10,11$ were all $5 \mathrm{~mm}$. Water $(0.1 \mathrm{~mL}), 0.1 \mathrm{~mL}$ of $0.01 \mathrm{~g} / \mathrm{mL}$ magnesium nanoparticle aqueous solution, and $0.1 \mathrm{~mL}$ of $0.02 \mathrm{~g} / \mathrm{mL}$ magnesium nanoparticle aqueous solution were injected intramuscularly into samples $9,10,11$, respectively. Once the pre-prepared nanoparticle solutions were injected into the samples, an infrared camera was turned on to monitor the surface temperatures.

Cases A-C were in vitro experiments, while Case D was an in vivo experiment. For this latter case, the in vivo experi-
A

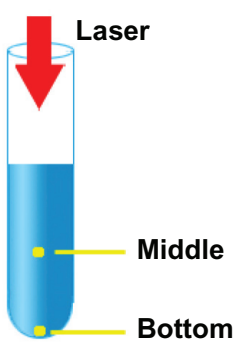

B

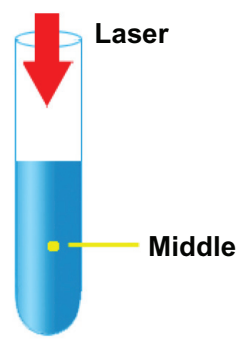

Figure 2 Experimental device scheme for Case A (A) and Case B (B). ment was conducted on one healthy male New Zealand white rabbit with weight about $3 \mathrm{~kg}$, which was bought from Fang Yuanyuan Farm, Beijing, China. The animal experiment was approved by the Ethical Committee of Tsinghua University under contract, Beijing, China. Figure 3 presents the schematic for the Case D experiment. Firstly, the rabbit was anesthetized with $25 \%(\mathrm{w} / \mathrm{w})$ isoflurane solution via intraperitoneal injection. Then, we used hair-removal cream to carefully remove hair from the rabbit leg. Once the $0.02 \mathrm{~g} / \mathrm{mL}$ magnesium nanoparticle aqueous solution was prepared and dispersed via ultrasound, $1 \mathrm{~mL}$ of the solution was injected into the target tissue of the left hind leg of the rabbit. The right hind leg was loaded with $1 \mathrm{~mL}$ water as the comparison experiment. The infrared camera and the thermocouple thermometers were used to monitor the surface and internal temperatures, respectively, of the rabbit. The infrared camera was placed in front of the rabbit's leg at a distance of about $60 \mathrm{~cm}$ and the thermocouples were inserted into the femoral muscle to measure the specific tissue sites. The depth of thermocouple 1 was $3 \mathrm{~mm}$ in the center of the laser spot, and the depths of thermocouples 2 and 3 were $10 \mathrm{~mm}$ and $5 \mathrm{~mm}$, respectively, beside the site of the laser irradiation. The room temperature was also monitored with a thermocouple thermometer.

\section{Results}

\section{Theoretical results}

Table 2 lists the thermal and optical properties of the tissues, water, and nanoparticles. ${ }^{17,19,20}$ To analyze the influence of

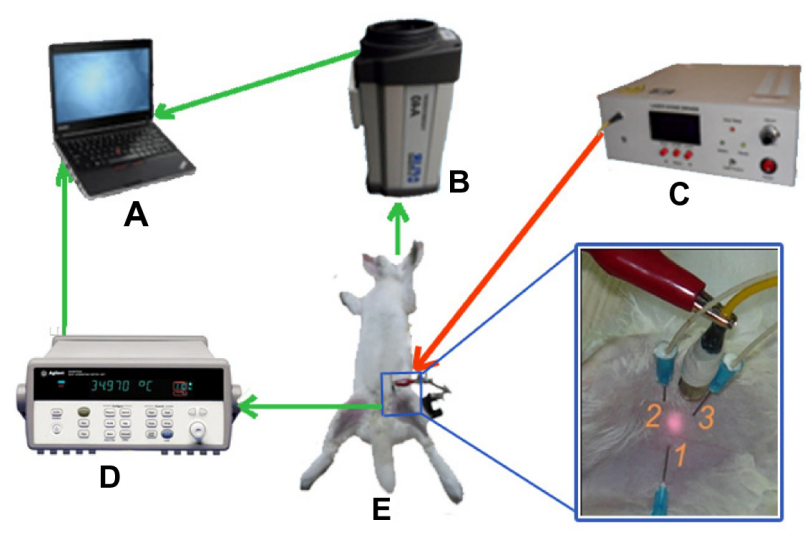

Figure 3 Schematic representation of the in vivo animal experiment. The rabbit (E) was anesthetized with isoflurane and hair was removed from its leg. The diode laser system (C) was used to emit laser radiation as a heating source. The infrared camera $(\mathbf{B})$ recorded the thermal images of the heated materials in real time and the internal temperature was monitored by thermocouple thermometer (D). The depth of thermocouple I was $3 \mathrm{~mm}$ in the center of the laser pot and the depths of thermocouples 2 and 3 were $1 \mathrm{~cm}$ and $0.5 \mathrm{~cm}$ beside the pot of the laser, respectively. The thermal images and internal temperature data were shown on the laptop computer $(\mathbf{A})$. 
Table 2 Parameters for tissue, water, and nanoparticles (NPs)

\begin{tabular}{llll}
\hline Property & Tissue & Water & NPs \\
\hline Thermal conductivity $\left(\lambda\left(\mathrm{W} / \mathrm{m} \cdot{ }^{\circ} \mathrm{C}\right)\right)$ & 0.59 & 0.6 & 159 \\
Blood perfusion rate $\left(\mathrm{W}_{\mathrm{b}}\left(\mathrm{kg} / \mathrm{s} \cdot \mathrm{m}^{3}\right)\right)$ & 0.5 & - & - \\
Mass density $\left(\rho\left(\mathrm{kg} / \mathrm{m}^{3}\right)\right)$ & 1050 & 1000 & 1736 \\
Heat capacity $\left(\mathrm{c}\left(\mathrm{J} /\left(\mathrm{kg} \cdot{ }^{\circ} \mathrm{C}\right)\right)\right)$ & 3200 & 4200 & 1025 \\
Metabolic heat production rate & 684.2 & - & - \\
$\left(\mathrm{Q}_{\mathrm{m}}\left(\mathrm{W} / \mathrm{m}^{3}\right)\right)$ & & & \\
Absorption coefficient $\left(\mathrm{Coe}_{\text {abs }}\left(\mathrm{mm}^{-1}\right)\right)$ & 0.1 & - & $3.67 \mathrm{E7}$ \\
Scattering coefficient $\left(\mathrm{Coe}_{\mathrm{sca}}\left(\mathrm{mm}^{-1}\right)\right)$ & 20.4 & - & I.37E7 \\
\hline
\end{tabular}

the nanoparticles on the heating effect, we simulated the temperature distribution of tissues loaded with nanoparticles as well as without nanoparticles for comparison. The results for the tissues loaded with and without nanoparticles are shown in Figures 4 and 5, respectively. During the simulation, the diameter of the particles and the number of particles per unit volume were prescribed as $80 \mathrm{~nm}$ and $10^{16} / \mathrm{m}^{3}$, respectively. Figure 4 shows the temperature field of the simulated tissues with and without nanoparticles during hyperthermia. It was found that the nanoparticle-loaded tissues reached a maximum temperature of $78.7^{\circ} \mathrm{C}$, while the tissues without nanoparticles only reached $60.4^{\circ} \mathrm{C}$. Obviously, such evident temperature differences were caused by the addition of the nanoparticles. Figure 5 depicts the transient maximum temperature during the irradiation process for the two cases. This value is appropriate for the safety of the biological tissues. ${ }^{17}$ If the simulation conditions were different, the temperature distributions would also differ. Thus, it was clear that the nanoparticles enhanced the laser heat disposition. All the simulated results demonstrate that the magnesium nanoparticles could serve as a highly promising heating enhancer for a targeted hyperthermia treatment.

A

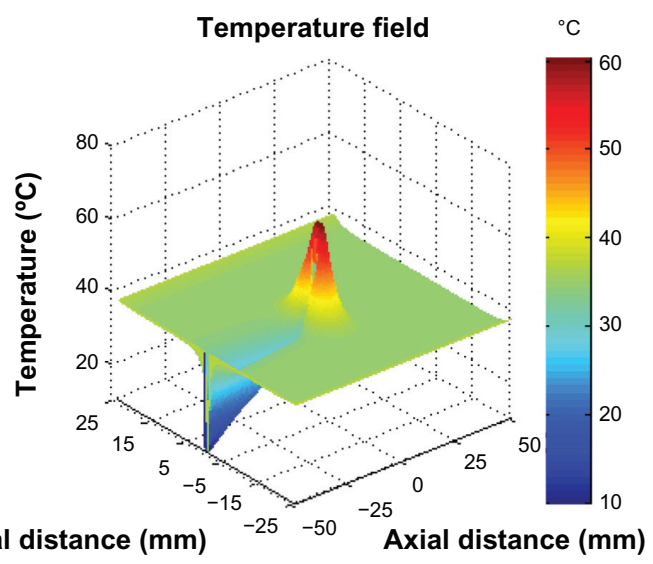

\section{Experimental results}

\section{Mixing magnesium nanoparticles with oil}

In this experiment, the laser irradiation time was set as 360 seconds and the temperature was recorded for a total of 600 seconds. The temperature of the surrounding environment was stabilized at $27.5^{\circ} \mathrm{C}$. As shown in Figure 6, the temperature of the oil without nanoparticles under laser irradiation remained almost unaltered. However, the temperature of the magnesium nanoparticle-loaded oil increased from $27.5^{\circ} \mathrm{C}$ to nearly $33^{\circ} \mathrm{C}$. The temperatures at the bottom were almost the same among the different concentrations of the magnesium nanoparticles. It appears that the temperature increase showed a concentration-saturated effect. The temperature difference between the middle and the bottom of the liquid decreased when the concentration of magnesium nanoparticles increased, which was due to the good thermal conductivity of magnesium nanoparticles.

\section{Mixing magnesium nanoparticles with egg white and egg yolk}

In these experiments, the laser irradiation time was set as 240 seconds and the temperature was recorded for a total of 380 seconds. The room temperature was about $26.7^{\circ} \mathrm{C}$. Figure 7A and $\mathrm{B}$ presents the temperature change of the egg white under laser irradiation with and without nanoparticles. It was interesting to note that the temperature immediately increased by $3.5^{\circ} \mathrm{C}$ for the egg white mixed with magnesium nanoparticles. As reflected in Figure 7B, the temperature of the mixture increased to $29.5^{\circ} \mathrm{C}$ under laser irradiation. This homogeneous mixture had a combustive property, as indicated in Figure 8A. A similar phenomenon occurred with the egg yolk. When subjected to laser irradiation, the temperature of the egg yolk hardly changed, as shown in Figure 7C. However, the temperature would quickly increase by $4^{\circ} \mathrm{C}$ when the egg

B

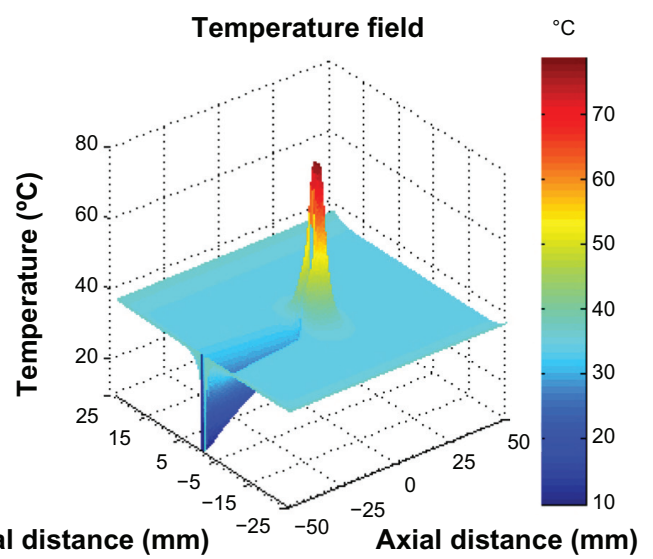

Figure 4 Temperature field during laser interstitial thermal therapy: (A) without nanoparticles and (B) with nanoparticles. 


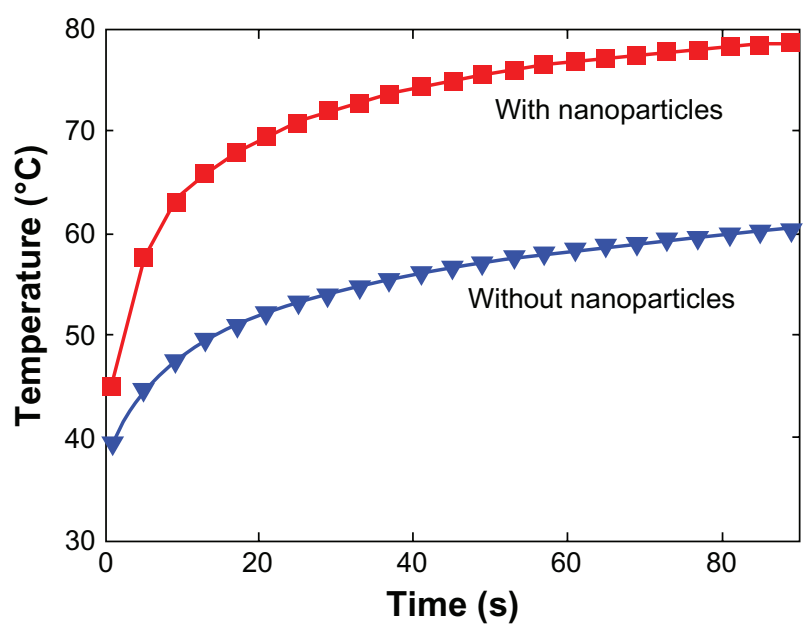

Figure 5 Transient maximum temperatures during irradiation.

yolk was mixed with the magnesium nanoparticles in advance, and the temperature increased to $31^{\circ} \mathrm{C}$ under laser irradiation, as shown in Figure 7D. It can be seen from Figure $8 \mathrm{~B}$ that the egg yolk mixed with magnesium nanoparticles burned at the laser irradiation spot. During the experiment, when we dropped two drops of phenolphthalein on the surface of the egg yolk mixture, it grew red (Figure $8 \mathrm{C}$ ). A reaction between water and $\mathrm{Mg}$ occurs. It is beneficial for treating tumors because this reaction releases amounts of heat.
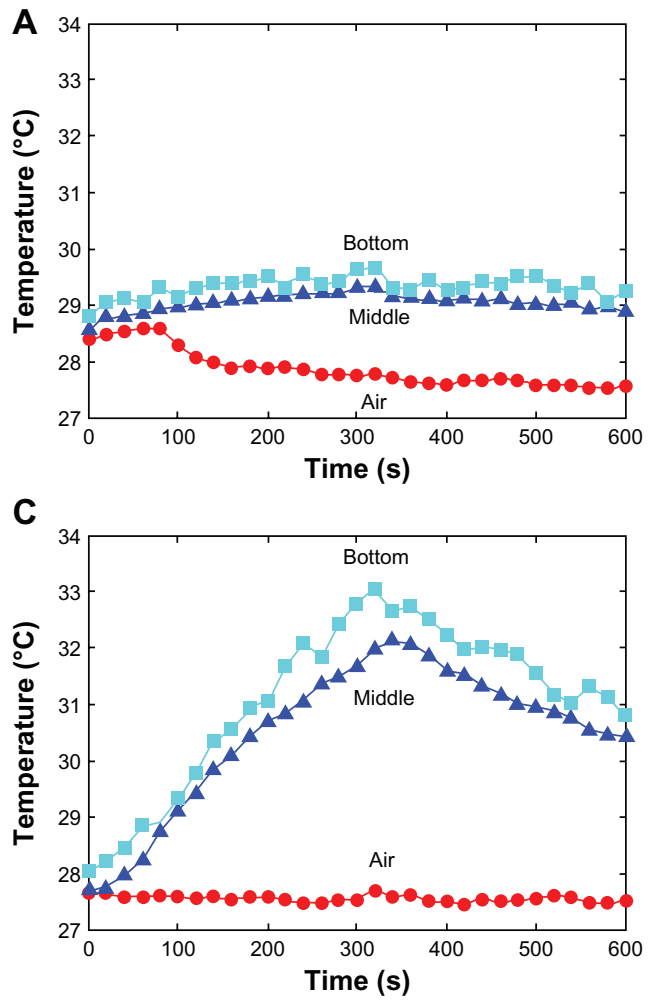

\section{Pig tissues in vitro}

For this case, the laser irradiation time was set as 360 seconds and the temperature was recorded for a total of 640 seconds. The temperature curves derived from the infrared camera images for samples 9,10 , and 11 of Case $\mathrm{C}$ are shown in Figure 9. The temperature changes that occurred in the tissues injected with magnesium nanoparticles appear greater than those that occurred in the tissues injected with water. Figure 10 presents the infrared images after 60 seconds of laser irradiation for the three samples. It is clear that the pig tissues injected with the $0.02 \mathrm{~g} / \mathrm{mL}$ magnesium nanoparticle aqueous solution produced the most significant temperature change.

\section{Hind leg of rabbit in vivo}

The room temperature during this experiment was $29.8^{\circ} \mathrm{C}$ (labeled "4" in Figure 11A and B). Figure 11A and B present the temperatures of the hind leg of the rabbit with $1 \mathrm{~mL}$ water and with $1 \mathrm{~mL}$ of $0.02 \mathrm{~g} / \mathrm{mL}$ magnesium nanoparticle aqueous solution, respectively, under the same level of laser irradiation. Clearly, the thermal effect with the magnesium nanoparticle aqueous solution appears much greater. Figure 12 shows infrared temperature images with and without magnesium nanoparticle aqueous solution.
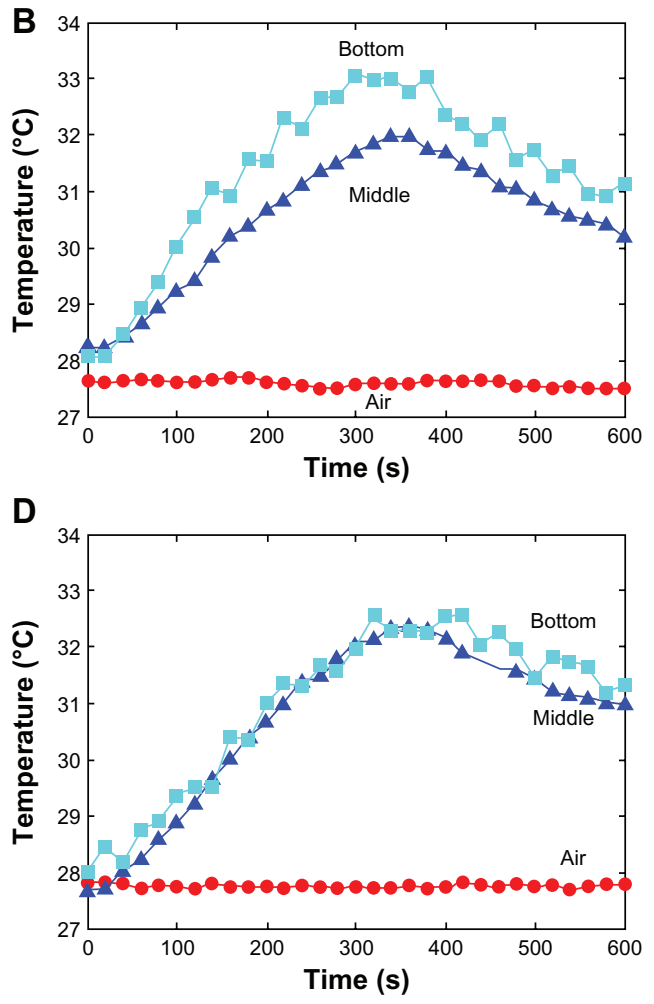

Figure 6 Plots of temperature for oil (A), suspensions of magnesium nanoparticles at $0.02 \mathrm{~g} / \mathrm{mL}(\mathbf{B}), 0.05 \mathrm{~g} / \mathrm{mL}(\mathbf{C})$, and $0.2 \mathrm{~g} / \mathrm{mL}(\mathbf{D})$ in $10 \mathrm{~mL}$ oil solution as a function of irradiation time under irradiation by diode laser at power of $1.5 \mathrm{~W}$. 

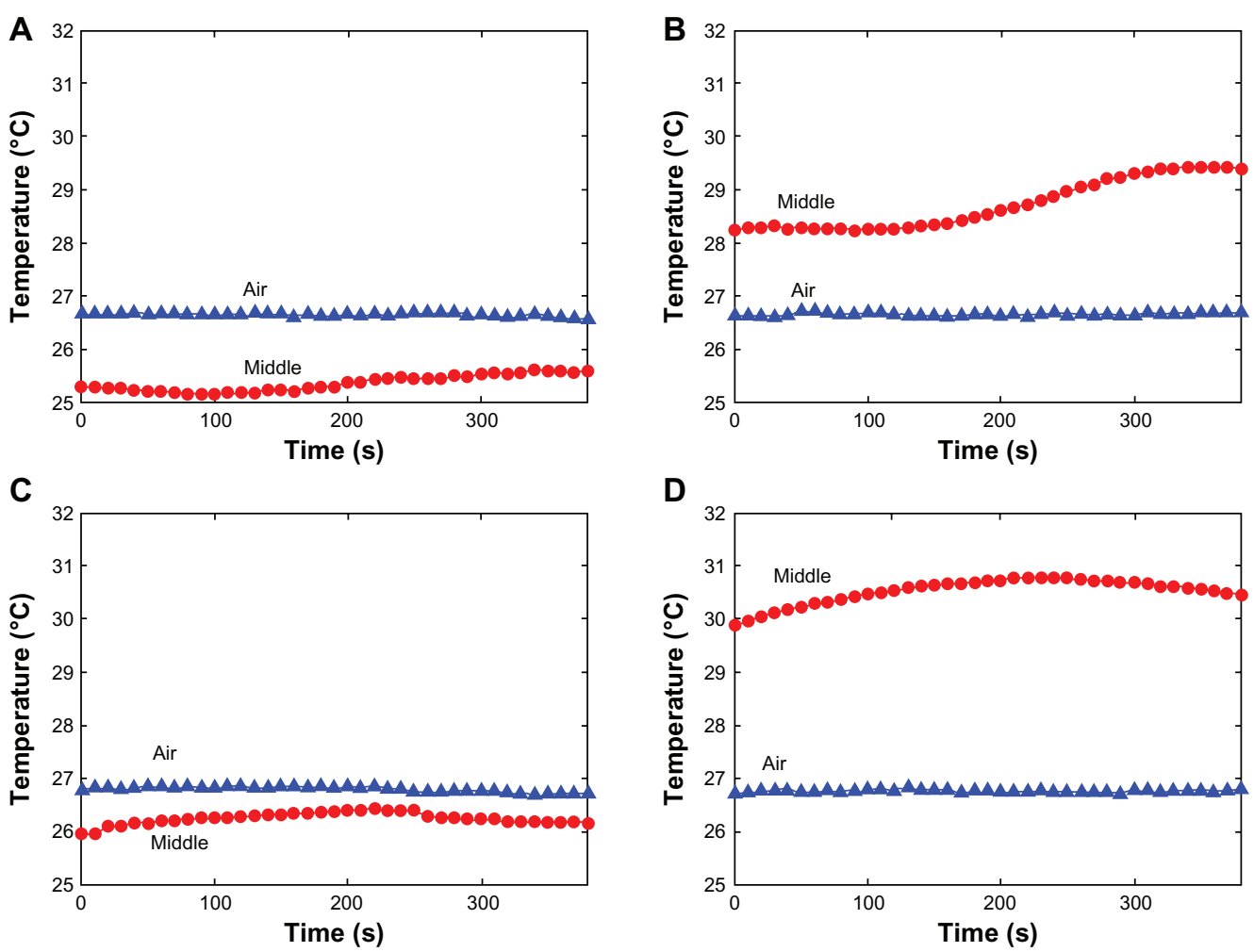

Figure 7 Plots of temperature increase for the egg white (A), the egg white with magnesium nanoparticles at $0.02 \mathrm{~g} / \mathrm{mL}$ (B), egg yolk (C), and egg yolk with magnesium nanoparticles at $0.02 \mathrm{~g} / \mathrm{mL}$ (D) in $10 \mathrm{~mL}$ beakers, as a function of irradiation time, under irradiation by diode laser at power of $1.5 \mathrm{~W}$.

The temperature of the hind leg of the rabbit injected with magnesium nanoparticle aqueous solution was much higher than that of the leg not injected with magnesium nanoparticle aqueous solution.

\section{Discussion}

Overall, according to the theoretical evaluation and experimental tests, magnesium nanoparticles are a highly promising material for use in hyperthermia. As far as the authors are aware, this is the first time the heating enhancement effect of such a material has been reported in nanomedicine. Compared with many existing popular nanomaterials, such as gold, magnesium has many unique advantages.

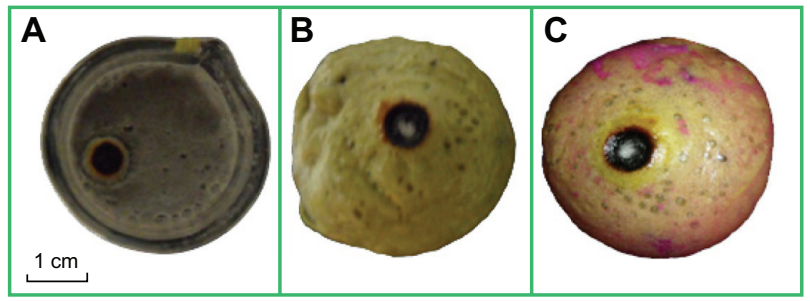

Figure 8 The egg white (A) and egg yolk (B) mixed with $0.02 \mathrm{~g} / \mathrm{mL}$ magnesium nanoparticles after laser irradiation at $1.5 \mathrm{~W}$ for 240 seconds. (C) The phenomenon observed after two drops of phenolphthalein were added to the surface of the egg yolk mixture.
Firstly, the density of magnesium is much lower than that of gold and therefore more particles can be loaded into the target tissues. Importantly, the density of magnesium is approximately $1.7 \mathrm{~g} / \mathrm{cm}^{3}$, which is very similar to that of human bone $\left(1.75 \mathrm{~g} / \mathrm{cm}^{3}\right)$. Besides this, magnesium is highly abundant in nature and will thus be cost-effective for clinical utilization. ${ }^{21}$ Secondly, magnesium is beneficial to human health. In content, it is second only to potassium in the human body. As a kind of "positive ion" in human

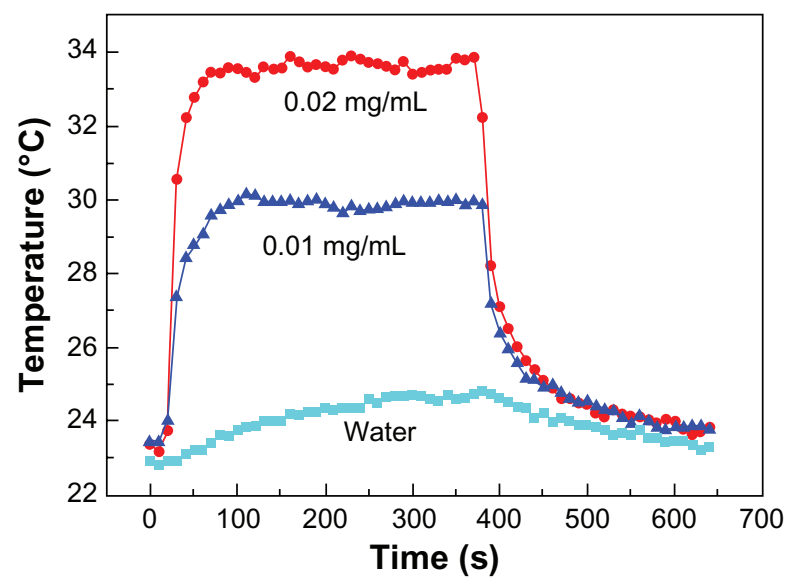

Figure 9 Surface temperature, derived from the thermal images, of the pig tissue at the center of the laser pot. 


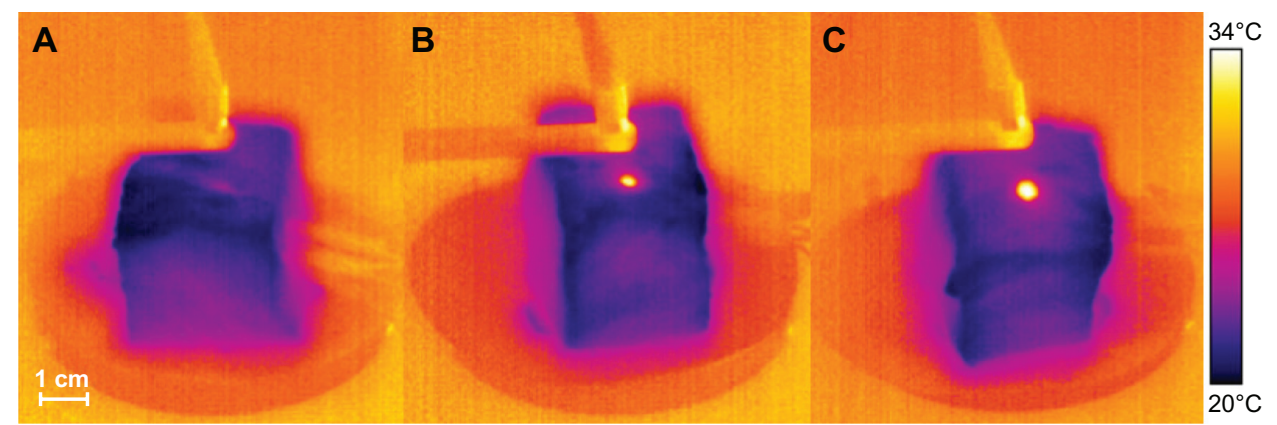

Figure 10 Thermal images of the pig tissue injected with water (A) $0.01 \mathrm{~g} / \mathrm{mL}$ fresh magnesium nanoparticle aqueous solution (B) and $0.02 \mathrm{~g} / \mathrm{mL}$ fresh magnesium nanoparticle aqueous solution (C) taken after I minute of laser irradiation at I W.

cells, it plays an important role in the synthesis of protein, activation of multiple enzymes, regulation of the activities of the neuromuscular and central nervous systems, and in ensuring normal myocardial contraction and temperature regulation.

Li et al's preliminary cytotoxicity study showed that magnesium has no inhibitory effects on bone marrow cell growth and no signs of cellular lysis were observed. ${ }^{22}$ Further, Abumaria et al's latest work suggests that elevation of brain magnesium might even be a novel approach for enhancing synaptic plasticity in a regional-specific manner leading to enhancement of extinction efficacy without enhancing or impairing fear memory formation. ${ }^{23}$ Importantly, it is a kind of biodegradable material in the human body second to none compared with any other metal material. The standard electrode potential of magnesium is low, and it can be corrosively degraded and absorbed into the body in the presence of chloride ions in the physiological environment.

Qiao et al's work reported some results of testing the cytotoxicity, hemolysis, and acute toxicity on magnesium samples, and quite attractive features were obtained..$^{24}$ In fact, magnesium and its alloys have been increasingly used as body stents because of the advantages already mentioned. ${ }^{24}$ Clearly, the use of magnesium nanoparticles proposed in the present study opens new pathways toward the full use of such material in medical fields.

However, it should be pointed out that there are still many problems that need to be solved before a hyperthermia modality such as the one described here is applied in clinics. We found that an amount of heat is released at the moment the nanoparticles were injected, which may result in tissues being burned. The heat energy comes from the chemical reaction between the magnesium nanoparticles and water contained in the tissue and this phenomenon would bring about a certain level of corrosion of the material. Further, if the rate of material degradation is too fast, the heating enhancement effect may not be maintained for long or fully occur. Moreover, the increased temperature would encourage the magnesium nanoparticles to react with the water in the tissues. Such a reaction could cause further tissue
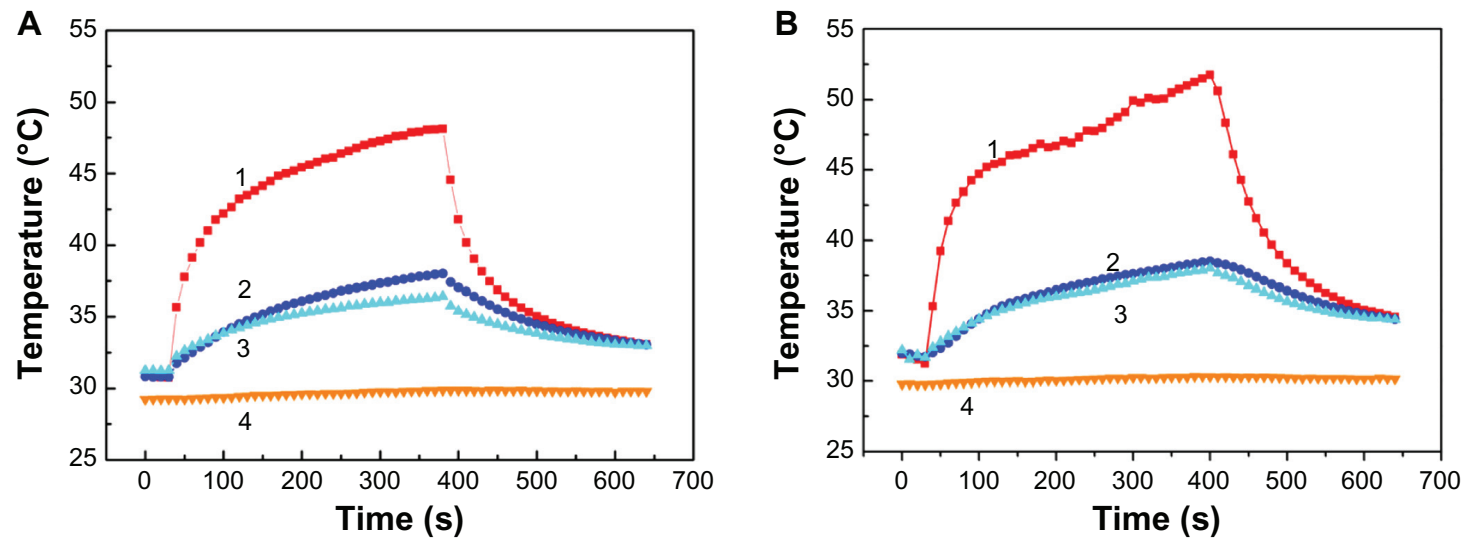

Figure I I Temperature measurements of the rabbit leg injected with I $\mathrm{mL}$ water $(\mathbf{A})$ and with I $\mathrm{mL}$ magnesium nanoparticle aqueous solution (B) irradiated with the laser at $1.5 \mathrm{~W}$.

Notes: The depth of thermocouple I was $3 \mathrm{~mm}$ in the center of the laser pot and the depths of thermocouples 2 and 3 were $10 \mathrm{~mm}$ and $5 \mathrm{~mm}$, respectively, beside the pot of the laser. Curve 4 indicates the room temperature. 
A

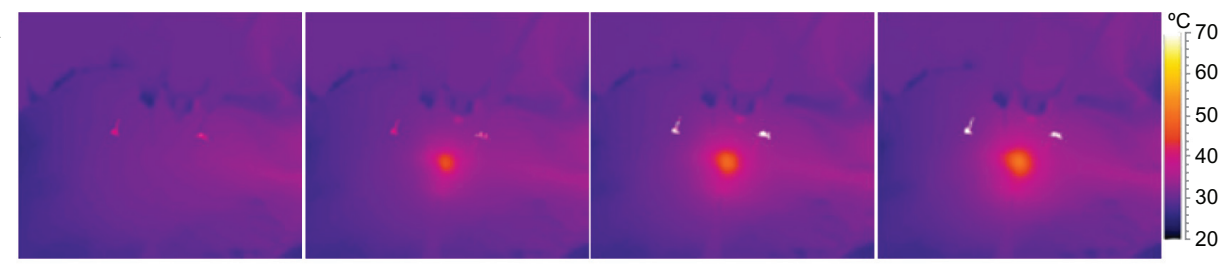

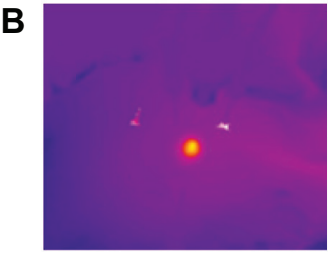

$2 \mathrm{~s}$

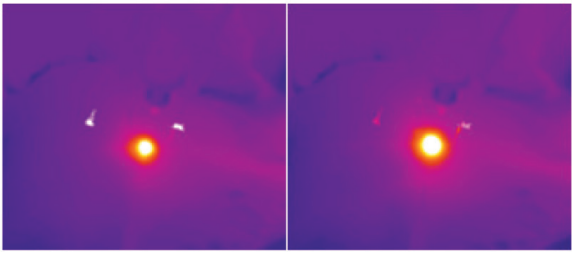

$2 \min$

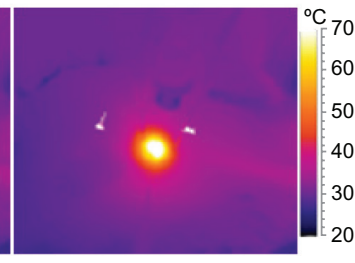

$6 \min$

Figure 12 Thermographic surveillance of photothermal heating on the hind leg of the rabbit injected with water (A) or with magnesium nanoparticle aqueous solution (B).

degeneration, although this would clearly be of benefit in the ablation of target tissues. ${ }^{25}$

Therefore, it is important that the degradation rate of the magnesium nanoparticles used in hyperthermia is controlled. In this regard, a protective coating on the nanoparticles might be a feasible way to avoid their reacting with water as well as to control the degradation rate and further improve biocompatibility. ${ }^{26}$ Another possibility is alkali-heat-treated magnesium (the magnesium is first immersed in supersaturated $\mathrm{NaHCO}_{3}-\mathrm{MgCO}_{3}$ for 24 hours and then heat treated at $773 \mathrm{~K}$ for 10 hours), which may have an improved corrosion resistance. ${ }^{23}$ In Qiao et al's study, alkali-treated magnesium caused distinct morphological changes in cells and a small hemolytic effect $(2.2 \%)$, which is less than the allowable 5\%. ${ }^{24}$ Other useful surface modification methods to control the corrosion rate include micro arc oxidation, phosphating treatment, electrodepositing, and polymer coating. ${ }^{16}$

Some studies have looked at the biodegradation of surface-modified magnesium and its alloys. In Geng et al's study, magnesium with $\beta$-tricalcium phosphate coating showed good biodegradation behavior in vitro, thus may slow down the biodegradation rate of magnesium. ${ }^{27}$ Grillo et al used fluoride conversion coatings to reduce corrosion rates and found that fluoride release from conversion coatings did not show cytotoxic effects. ${ }^{28}$ Further, Hannover Medical School in Germany has developed a biodegradable magnesiumhydroxyapatite metal matrix composite material that may adjust the degradation rate through the size and distribution of the hydroxyapatite particles. ${ }^{29}$

There are also a number of other studies that have reported less than ideal biocompatibility of pure magnesium. ${ }^{22,30}$ However, generally, the samples used in these experiments were cultured cells, which are sensitive to the environment. As already discussed, pure magnesium reacts easily with water mediums, which then results in an increase in $\mathrm{pH}$ value and release of ions. However, this situation is different from that described here for hyperthermia using magnesium nanoparticles. Firstly, as the magnesium nanoparticles are injected into the center of the tumor, environmental changes - including to $\mathrm{pH}$ and the amount of ions released - in the surrounding normal tissues are less than in the site of the tumor. Secondly, the increase in $\mathrm{pH}$ value and release of ions in the tumor region may contribute to tumor death; this needs to be investigated further.

The present nanohyperthermia modality has a generalized purpose. The same strategy can also be extended to other hyperthermia fields, such as electrical, magnetic, or focused acoustic nanoparticle hyperthermia, and thermochemical heating. One of the reasons is that the thermal conductivity of magnesium and its alloys is quite high, so they can effectively enhance heat transfer, which is transformed from other forms of energy. Targeted thermochemical ablation therapy, which is based on the release of heat from chemical reactions into the target tissues, involves two typical methods: acid-alkali reaction-enabled thermal ablation and alkali metal-enabled thermal ablation. ${ }^{25}$ On account of their better thermal conductivity, magnesium nanoparticles could not only be used as a kind of alkali metal involved in chemical reactions to produce heat but also to improve the thermal conductivity of the target tissues.

Although iron is more magnetic than more common materials such as magnetite and maghemite, it is easily oxidized in vivo and its magnetic properties are reduced, which restricts its use in magnetic nanohyperthermia. The general solution is to cover the iron nanoparticle with a 
shell of gold, ${ }^{31}$ silver, ${ }^{32}$ or one of their hybrids to protect the magnetic core against oxidation. However, these materials are not biodegradable. Compared with them, magnesium is much cheaper and safer for use in the human body.

Finally, particularly of note for the emerging role of the presently proposed magnesium nanoparticles in nanomedicine is their potential for implementation as a new and completely safe nanocarrier drug-delivery system. In fact, finding a safe and highly efficient delivery system for delivering drugs or even genes and proteins (growth factors) to the target tissue site for specific medical purpose has become an exciting frontier. Important discoveries continue to be made in this area of research. ${ }^{33-38}$ Clearly, with perfect biodegradability and medical safety, magnesium nanoparticles may contribute significantly to this important endeavor. More effort, either fundamental or practical, is thus necessary to extend the medical applications of these nanoparticles in the future.

\section{Conclusion}

In this study, biodegradable magnesium nanoparticles have been proposed for the first time as a heating enhancer targeted to high-performance hyperthermia, especially laser thermal ablation. The new strategy would help to resolve the problems facing current tumor nanomedicine such as side effects and toxicity. In addition, expulsion of the nanoparticles out of the human body, which carries potential dangers, may no longer be necessary. This will significantly simplify the surgical process and reduce treatment costs. Both theoretical simulations and conceptual experiments demonstrate the heating enhancement effect of the magnesium nanoparticles for laser thermal ablation. Some new thermal phenomena were observed and exciting insights into biodegradable nanoparticle-enhanced laser thermal therapy for future practice revealed. Compared with many existing metal agents used in nanomedicine, magnesium nanoparticles have excellent degradability in vivo. Further, the magnesium nanoparticle-enhanced laser hyperthermia therapy discussed has a generalized purpose that can be extended to other areas of nanomedicine. In this sense, magnesium nanoparticle-enhanced hyperthermia opens a "green" way for future tumor therapy.

\section{Acknowledgment}

This work is supported by the National Natural Science Foundation of China under Grant 81071255, the Specialized Research Fund for the Doctoral Program of Higher Education, and the Research Fund from Tsinghua University under Grant 523003001.

\section{Disclosure}

The authors report no conflicts of interest in this work.

\section{References}

1. Jemal A, Siegel R, Xu J, Ward E. Cancer statistics, 2010. CA Cancer J Clin. 2010;60(5):277-300.

2. Ferrari M. Cancer nanotechnology: opportunities and challenges. Nat Rev Cancer. 2005;5(3):161-171.

3. Jain KK. Role of nanobiotechnology in developing personalized medicine for cancer. Technol Cancer Res Treat. 2005;4(6):645-650.

4. Hirsch LR, Stafford RJ, Bankson JA, et al. Nanoshell-mediated nearinfrared thermal therapy of tumors under magnetic resonance guidance. Proc Natl Acad Sci U S A. 2003;100(23):13549-13554.

5. Loo C, Lowery A, Halas N, West J, Drezek R. Immunotargeted nanoshells for integrated cancer imaging and therapy. Nano Lett. 2005;5(4):709-711.

6. Huang X, El-Sayed IH, Qian W, EI-Sayed MA. Cancer cell imaging and photothermal therapy in the near-infrared region by using gold nanorods. J Am Chem Soc. 2006;128(6):2115-2120.

7. Chen J, Wang D, Xi J, et al. Immuno gold nanocages with tailored optical properties for targeted photothermal destruction of cancer cells. Nano Lett. 2007;7(5):1318-1322.

8. Chen J, Glaus C, Laforest R, et al. Gold nanocages as photothermal transducers for cancer treatment. Small. 2010;6(7):811-817.

9. Liu Z, Cai W, He L, et al. In vivo biodistribution and highly efficient tumour targeting of carbon nanotubes in mice. Nat Nanotechnol. 2007;2(1):47-52.

10. Goodman CM, McCusker CD, Yilmaz T, Rotello VM. Toxicity of gold nanoparticles functionalized with cationic and anionic side chains. Bioconjug Chem. 2004;15(4):897-900.

11. Liao F, Folsom AR, Brancati FL. Is low magnesium concentration a risk factor for coronary heart disease? The Atherosclerosis Risk in Communities (ARIC) Study. Am Heart J. 1998;136(3):480-490.

12. Hampton EM, Whang DD, Whang R. Intravenous magnesium therapy in acute myocardial infarction. Ann Pharmacother. 1994;28(2): 212-219.

13. Staiger MP, Pietak AM, Huadmai J, Dias G. Magnesium and its alloys as orthopedic biomaterials: a review. Biomaterials. 2006;27(9):1728-1734.

14. Heublein B, Rohde R, Kaese V, Niemeyer M, Hartung W, Haverich A. Biocorrosion of magnesium alloys: a new principle in cardiovascular implant technology? Heart. 2003;89(6):651-656.

15. Jeon KJ, Moon HR, Ruminski AM, et al. Air-stable magnesium nanocomposites provide rapid and high-capacity hydrogen storage without using heavy-metal catalysts. Nat Mater. 2011;10(4):286-290.

16. Gu XN, Zheng YF. A review on magnesium alloys as biodegradable materials. Front Mater Sci China. 2010;4(2):111-115.

17. Wang X, Gao X, Liu J. Monte-Carlo simulation on gold nanoshells enhanced laser interstitial thermal therapy on target tumor. $J$ Comput Theor Nanosci. 2010;7(6):1025-1031.

18. SINONANO, N\&C Beijing Nachen S\&T Ltd. Available from: http:// www.nanoinchina.com. Accessed August 6, 2012.

19. Wang Q, Deng ZS, Liu J. Effects of nonuniform tissue properties on temperature prediction in magnetic nanohyperthermia. J Nanotechnol Eng Med. 2011;2(2):021012.

20. The Engineering Toolbox. Thermal conductivity of some common materials and gases [web page on the Internet]. Available from: http:// www.engineeringtoolbox.com/thermal-conductivity-d_429.html. Accessed December 29, 2011.

21. Maker GL, Kruger J. Corrosion of magnesium. Int Mater Rev. 1993; 38(3):138-153. 
22. Li L, Gao J, Wang Y. Evaluation of cyto-toxicity and corrosion behavior of alkali-heat-treated magnesium in simulated body fluid. Surf Coat Technol. 2004;185:92-98.

23. Abumaria N, Yin B, Zhang L, et al. Effects of elevation of brain magnesium on fear conditioning, fear extinction, and synaptic plasticity in the infralimbic prefrontal cortex and lateral amygdala. $J$ Neurosci. 2011;31(42):14871-14881.

24. Qiao LY, Gao JC, Wang Y, Wang SL, Wu S, Xue Y. Biocompatibility evaluation of magnesium-based materials. Mater Sci Forum 2007;(546-549):459-462.

25. Rao W, Liu J, Zhou YX, Yang Y, Zhang H. Anti-tumor effect of sodium-induced thermochemical ablation therapy. Int J Hyperthermia. 2008;24(8):675-681.

26. Gray JE, Luan B. Protective coatings on magnesium and its alloys a critical review. J Alloys Compd. 2002;336(1-2):88-113.

27. Geng F, Tan LL, Jin XX, Yang JY, Yang K. The preparation, cytocompatibility, and in vitro biodegradation study of pure beta-TCP on magnesium. J Mater Sci Mater Med. 2009;20(5):1149-1157.

28. Grillo CA, Alvarez F, de Mele MA. Biological effects of magnesium particles degradation on UMR-106 cell line: influence of fluoride treatments. Colloids Surf B Biointerfaces. 2011;88(1):471-476.

29. Witte F, Feyerabend F, Maier P, et al. Biodegradable magnesiumhydroxyapatite metal matrix composites. Biomaterials. 2007;28(13): 2163-2174.

30. Lorenz C, Brunner JG, Kollmannsberger P, Jaafar L, Fabry B, Virtanen S. Effect of surface pre-treatments on biocompatibility of magnesium. Acta Biomater. 2009;5(7):2783-2789.
31. Ravel B, Carpenter EE, Harris VG. Oxidation of iron in iron/gold core/ shell nanoparticles. J Appl Phys. 2002;91(10):8195-8197.

32. Choi JY, Kim K, Shin KS. Surface-enhanced raman scattering Inducible by recyclable Ag-coated magnetic particles. Vib Spectrosc. 2010;53(1):117-120.

33. Hosseinkhani H. DNA nanoparticles for gene delivery to cells and tissue. Int J Nanotechnol. 2006;3(4):416-461.

34. Subramani KA, Pathak SA, Hosseinkhani H. Recent trends in diabetes treatment using nanotechnology. Dig J Nanomat Biostructures. 2012;7(1):85-95.

35. Hosseinkhani H, Tabata Y. Self assembly of DNA nanoparticles with polycations for the delivery of genetic materials into cells. $J$ Nanosci Nanotechnol. 2006;6(8):2320-2328.

36. Hosseinkhani H, Hosseinkhani M. Biodegradable polymer-metal complexes for gene and drug delivery. Curr Drug Saf. 2009;4(1):79-83.

37. Mahmoudi M, Hosseinkhani H, Hosseinkhani M, et al. Magnetic resonance imaging tracking of stem cells in vivo using iron oxide nanoparticles as a tool for the advancement of clinical regenerative medicine. Chem Rev. 2011;111(2):253-280.

38. Subramani K, Hosseinkhani H, Khraisat A, Hosseinkhani M, Pathak Y. Targeting nanoparticles as drug delivery systems for cancer treatment. Curr Nanosci. 2009;5(2):135-140.
International Journal of Nanomedicine

\section{Publish your work in this journal}

The International Journal of Nanomedicine is an international, peerreviewed journal focusing on the application of nanotechnology in diagnostics, therapeutics, and drug delivery systems throughout the biomedical field. This journal is indexed on PubMed Central,

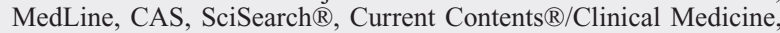

\section{Dovepress}

Journal Citation Reports/Science Edition, EMBase, Scopus and the Elsevier Bibliographic databases. The manuscript management system is completely online and includes a very quick and fair peer-review system, which is all easy to use. Visit http://www.dovepress.com/ testimonials.php to read real quotes from published authors. 